\title{
Occupational Health and Its Influence on Job (Dis)Satisfaction
}

\author{
Fernando Almeida ${ }^{1,2,3,4}$, Rosa Rodrigues ${ }^{2}$, Diana Moreira ${ }^{1,5 *}$ \\ ${ }^{1}$ University Institute of Maia, Maia, Portugal \\ ${ }^{2}$ Institute of Biomedical Sciences Abel Salazar, University of Porto, Porto, Portugal \\ ${ }^{3}$ Lusíadas Porto Hospital, Porto, Portugal \\ ${ }^{4}$ i3S-Instituto de Investigação e Inovação em Saúde, Porto, Portugal \\ ${ }^{5}$ Laboratory of Neuropsychophysiology, Faculty of Psychology and Educational Sciences, University of Porto, Porto, Portugal \\ Email: ^dianapmoreira@gmail.com
}

How to cite this paper: Almeida, F., Rodrigues, R., \& Moreira, D. (2019). Occupational Health and Its Influence on Job (Dis)Satisfaction. Advances in Applied Sociology, 9, 179-192.

https://doi.org/10.4236/aasoci.2019.96015

Received: March 28, 2019

Accepted: June 15, 2019

Published: June 18, 2019

Copyright () 2019 by author(s) and Scientific Research Publishing Inc. This work is licensed under the Creative Commons Attribution International License (CC BY 4.0).

http://creativecommons.org/licenses/by/4.0/

\begin{abstract}
Occupational health provides/promotes the highest level of physical, mental, and social well-being of the working class in all occupations; protects workers at their place of work, against any risk factor that is detrimental to their health; safeguards all kinds of damage to workers' health caused by working conditions and adapts the type of work to the physical and psychological fitness of each individual. This study discusses the concepts of job satisfaction and absenteeism, setting as goal the assessment of his importance in the workplace (occupational health). This study was conducted with 149 professionals from Portugal, encompassing several professional categories. The results show significant differences in the levels of job satisfaction, according variables such as professional category, working hours, motivation, and satisfaction. The results suggest the need for programs that promote wages perceived as fair and adequate benefit policies, in order to achieve improvements at both organizational and individual levels.
\end{abstract}

\section{Keywords}

Job Satisfaction, Motivation, Responsibility, Security, Stability

\section{Introduction}

In 1957, the International Labor Organization (ILO) and the World Health Organization (WHO) define and objectify the importance of occupational health $(\mathrm{OH})$, argue that the $\mathrm{OH}$ proposes to provide and promote the highest level of physical, mental, and social well-being of the working class in all occupations, protect workers at their place of work, against any risk factor that is detrimental 
to their health, safeguard all kinds of damage to workers' health caused by working conditions and adapt the type of work to the physical and psychological fitness of each individual (Nogueira, 1984).

Absenteeism is a behavioral event that has been studied mainly as a response to job dissatisfaction. It is a complex phenomenon that is present in almost all organizations, weakening them and damaging the work environment (Tylczak, 1993). Job absenteeism covers all causes of absence, such as: accidents, maternity leave, extended illness, court procedures, attention to family problems and exterior training courses; it does not cover vacations and holidays, strikes, weekly or compensated rest and courses within the company (Bulhões, 1986).

Job satisfaction can be defined as a positive emotional state that occurs from the interaction of professionals, including their expectations and their personality characteristics, with the environment and nature of the job itself (Happel, Martin, \& Pinikahana, 2000). According to Monteiro \& Caetano (1994), job satisfaction is a construct that seeks to convey a positive attitude towards work and experiences in the workplace. The causal factors of job satisfaction are related to the job itself and its contents, conditions and working environment, skills and management policies of the organization (Locke, 1969, 1976).

From the literature review, one can surmise that job dissatisfaction has repercussions not only on the person's health, but also on the quality of the care they provide and/or the performance of other duties, which may lead to high levels of absenteeism. Several studies report that job satisfaction plays a major role in the problem of absenteeism (Brayfield \& Crockett, 1955; Herzberg et al., 1957; Ilghen \& Hollenbeck, 1977; Porter \& Steers, 1973; Vroom, 1964). Job dissatisfaction may be responsible for high levels of absenteeism, leading to problems of morality, discipline, stress, and additional administrative productivity/costs (Tylczak, 1993).

Therefore, one's professional life is one of the main agents that contributes to a higher or lower health level, and may provide excess levels of despair, frustration, and stress or, on the other hand, provide optimal levels of satisfaction and success (Pines \& Aronson, 1989).

Given the above, the importance of this issue is easily understandable and it represents for us a source of interest and study. To this end, we assessed the importance of job satisfaction for absenteeism, within several groups of professionals from one hospital in Portugal.

\section{Method}

\subsection{Participants}

One hundred forty-nine participants (100 female) were recruited from the departments of Emergency, Neurosurgery, Traumatic Brain Injury (TBI), Human Resources and Ophthalmology of one hospital in Portugal. Currently, there is a greater concern for the health of individuals who work in health organizations. The hospital institution is one of these occupational health risk contexts. The work performed in hospitals requires that all professionals have enough clinical 
experience and maturity to face and make difficult decisions, frequently with ethical and moral implications (Albaladejo et al., 2004). The employee who works in hospital institutions is exposed to different occupational stressors that directly affect his well-being. Among all, many consecutive hours of work, insufficient staffing, lack of professional recognition, high professional exposure to chemical and physical risks, and constant contact with suffering, pain, and death. The performance of these professionals involves a series of activities that necessarily require a much greater mental and emotional control than in other professions (Benevides-Pereira, 2002). All participants signed informed consent agreement. The study was conducted in accordance with the Declaration of Helsinki (World Medical Association, revised 2000). Their average age was between 20 and 29 years $(S D=7.38)$. Results concerning descriptive statistics for sample characterization are presented in Tables 1-3. In Table 1 are presented descriptive statistics for sample characterization by gender, age, marital status, and educational qualifications; Table 2 presents distribution of the sample according to the variables related to labor regime, namely professional status, professional category, service time, office hours, exercises managerial positions, and pursues his professional activity in other institutions; and in Table 3 are presented mean, standard deviation, minimum, and maximum of the JDI (total and scales) and JIG (work in general).

\subsection{Instruments and Procedure}

All participants filled out the following assessment instruments: 1) semi-structured interview protocol, to develop accordingly, to collect data that allow(s) for a socio-demographic characterization of the sample and 2) the Job Descriptive Index (JDI, 1997) which contains a job in general scale (JIG-Job in General, 1997), translated and adapted by McIntyre and McIntyre (2003).

The socio-demographic questionnaire contains questions that allow the characterization of the sample, as well as matters concerning the evaluation of absenteeism (e.g., How many days were missed in the last year? What is the reason for these absences? How many days were missed this year? What is the reason for these absences?).

The Job Descriptive Index (JDI) is a translation of the new revision (1997) of the JDI. It is a scale initially developed by Smith, Kendall, \& Hulin (1969). Its adaptation and translation to Portuguese was performed by McIntyre and McIntyre (2003). After many years of research and application, the JDI is currently one of the most widely used measures in job satisfaction (Zedeck, 1987).

The English version of the JDI is composed of five scales (Characterization of Current Job, Wage, Opportunities for Promotion, Supervision, and Coworkers), which evaluate five important facets of job satisfaction and were derived from factor analysis. Each scale is composed of 18 items, except the wage and opportunities for promotion scales, which have only 9 items. These serve to diagnose important aspects of the job. In the Portuguese version, the scale did not undergo modifications, and evaluates exactly the same facets. 
The Job in General (JIG) scale was developed to assess total job satisfaction (Ironson, Smith, Brannick, Gibson, \& Paul, 1989), also adapted and translated into Portuguese by McIntyre and McIntyre (2003). Also composed of 18 items, it is a Portuguese adaptation of the English scale and translates a global assessment of job satisfaction (long-term basis).

Table 1. Descriptive statistics for sample characterization.

\begin{tabular}{|c|c|c|}
\hline & $N$ & $(\%)$ \\
\hline \multicolumn{3}{|l|}{ 1) Gender } \\
\hline a) Female & 97 & 65.1 \\
\hline b) Male & 49 & 32.9 \\
\hline c) No response & 3 & 2.00 \\
\hline \multicolumn{3}{|l|}{ 2) Age } \\
\hline a) Less than 19 years & 0 & 0.00 \\
\hline b) $20-29$ years & 63 & 42.6 \\
\hline c) 30 - 39 years & 37 & 25.0 \\
\hline d) 40 - 49 years & 29 & 19.6 \\
\hline e) 50 - 59 years & 19 & 12.8 \\
\hline f) $60-69$ years & 0 & 0.00 \\
\hline g) 70 years or more & 0 & 0.00 \\
\hline h) No response & 1 & 0.70 \\
\hline \multicolumn{3}{|l|}{$\underline{\text { 3) Marital status }}$} \\
\hline a) Married & 71 & 47.7 \\
\hline b) Divorced & 13 & 8.70 \\
\hline c) Single & 58 & 38.9 \\
\hline d) Widower & 2 & 1.30 \\
\hline e) Separated & 0 & 0.00 \\
\hline f) Committed & 5 & 3.40 \\
\hline \multicolumn{3}{|l|}{$\underline{\text { 4) Educational qualifications }}$} \\
\hline a) By the 4 th grade & 4 & 2.70 \\
\hline b) The 5th to 9 th grade & 23 & 15.4 \\
\hline c) The 10th to 12 th year & 33 & 22.1 \\
\hline d) Technical and Vocational Course & 0 & 0.00 \\
\hline e) Bachelor degree & 8 & 5.40 \\
\hline f) Graduation & 81 & 54.5 \\
\hline g) Master's degree & 0 & 0.00 \\
\hline h) $\mathrm{PhD}$ & 0 & 0.00 \\
\hline Total $(N)$ & & \\
\hline
\end{tabular}


Table 2. Distribution of the sample according to the variables related to labor regime.

\begin{tabular}{|c|c|c|}
\hline & $N$ & $(\%)$ \\
\hline \multicolumn{3}{|l|}{ 1) Professional status } \\
\hline a) Employment contract for a fixed term & 20 & 13.4 \\
\hline b) Individual contract of permanent employment & 39 & 26.2 \\
\hline c) Individual employment contracts expiring & 13 & 8.70 \\
\hline d) Administrative employment contract & 16 & 10.7 \\
\hline e) Provision of services & 4 & 2.70 \\
\hline f) Appointment & 21 & 14.1 \\
\hline g) Other situation & 31 & 28.8 \\
\hline c) No response & 5 & 3.40 \\
\hline \multicolumn{3}{|l|}{ 2) Professional category } \\
\hline a) Senior technician & 0 & 0.00 \\
\hline b) Health technician & 6 & 4.00 \\
\hline c) Technical diagnostics therapy & 0 & 0.00 \\
\hline d) Technical and Vocational & 0 & 0.00 \\
\hline e) Doctor & 13 & 8.70 \\
\hline f) Nurse & 65 & 43.6 \\
\hline g) Administrative (a) & 28 & 18.8 \\
\hline h) General services & 37 & 24.8 \\
\hline \multicolumn{3}{|l|}{ 3) Service time } \\
\hline a) Less than 5 years & 57 & 38.3 \\
\hline b) 5 - 9 years & 30 & 20.1 \\
\hline c) $10-14$ years & 17 & 11.4 \\
\hline d) $15-19$ years & 9 & 6.00 \\
\hline e) $20-24$ years & 11 & 7.40 \\
\hline f) 25 - 29 years & 7 & 4.70 \\
\hline g) $30-34$ years & 10 & 6.70 \\
\hline h) 35 - 40 years & 7 & 4.70 \\
\hline i) No response & 1 & 0.70 \\
\hline \multicolumn{3}{|l|}{ 4) Office hours } \\
\hline a) Day fixed shifts & 37 & 24.8 \\
\hline b) Day rotating shifts & 8 & 5.40 \\
\hline c) Night fixed shifts & 0 & 0.00 \\
\hline d) Night rotating shifts & 2 & 1.30 \\
\hline e) Day and night rotating shifts & 99 & 66.4 \\
\hline f) Other & 3 & 2.00 \\
\hline
\end{tabular}


5) Exercises managerial positions

a) Yes $10 \quad 6.70$

b) No $137 \quad 91.0$

b) No response $\quad 2 \quad 1.30$

6) Pursues his professional activity in other institutions

\begin{tabular}{ccc} 
a) Yes & 43 & 28.9 \\
b) No & 106 & 71.1 \\
Total $(N)$ & \multicolumn{2}{c}{149} \\
\end{tabular}

Table 3. Mean, standard deviation, minimum, and maximum of the JDI (total and scales) and JIG (work in general).

\begin{tabular}{cccccc}
\hline & $N$ & Min & Max & $M$ & $S D$ \\
\hline Labor current characterization & 149 & 6.00 & 79.00 & 39.74 & 11.57 \\
Salary & 149 & .00 & 46.00 & 17.73 & 9.99 \\
Promotion opportunities & 149 & .00 & 54.00 & 14.47 & 11.50 \\
Supervision & 149 & 3.00 & 70.00 & 38.59 & 14.30 \\
Work colleagues & 149 & .00 & 54.00 & 37.81 & 12.74 \\
General work & 149 & 3.00 & 54.00 & 40.91 & 10.52 \\
Full scale average & 149 & 8.50 & 50.00 & 31.54 & 7.53 \\
\hline
\end{tabular}

The JIG was developed to express global assessment of a job, on a long-term basis. Besides reflecting the five facets of work and their importance for each person, it also reflects their interactions and the contributions of individual and situational facets that make each individual satisfied or dissatisfied with their job. When intending to research job satisfaction, it is not possible to merely add the five scales of the JDI and reach a value of satisfaction. It is also necessary to possess a general assessment, which comprehends facets that were not assessed in the other scales, such as, an individual may be very dissatisfied with his/her wage and supervision and very satisfied with his/her coworkers, but, in general, may be highly satisfied with his/her job. Hence, the JIG scale is extremely helpful in this type of research.

The results of the JDI/JIG are expressed on a scale with values between 0 and 54. Scoring of the questions is done so that, the higher the obtained value is (e.g., 54), the higher the satisfaction the person feels with their job in general (JIG) or with that facet of their job; whereas a low score (e.g., 0) means that the individual is completely dissatisfied with their job in general (JIG) or with that facet of their job. The results of the JDI and the JIG should be interpreted on a group or organizational level and not individually. In these instruments, there is no neutral point, where high values mean that a person is satisfied and lower values mean a person is dissatisfied, but, in general, it can be guaranteed that the results translate people's feelings towards their job. Satisfaction or dissatisfaction is calculated based on values 32 and above (indicators of satisfaction) and 22 and be- 
low (indicators of dissatisfaction) on a scale of 0 to 54 .

The purpose of the JDI/JIG is to provide researchers with a broader understanding of how situations affect feelings and behavior. Job satisfaction offers important clues in terms of health and gain of an organization. The measures of the strengths and weaknesses tell professionals where improvements may be performed.

The questionnaires were administered to various groups of professionals, so as to not cause any hazard to the respective department, and encompassing various professional categories: Doctor, Nurse, Health technician, Administrative, and General Services.

Accordingly, a written authorization application was made to the Board of Directors and to the Ethics Committee of the SAGH, for the execution of this study, particularly, authorization for the administration of the questionnaires (Sociodemographic; JDI-Job Descriptive Index, 1997; and JIG-Job in General, 1997). After consent from those authorities, contact with the Directors of various services was established, in order to explain the purpose of the study and schedule participation in service meetings, in order to request the collaboration of the professionals. Afterwards, in the service meetings, the study was presented and its purpose was explained, as well as the instructions for filling out the questionnaires. The ethical and methodological principles were also confirmed, such as issues of confidentiality and the anonymity of the data to be collected, explaining that the answers given in no way identified the respondents. It was also stated that there were no correct or incorrect answers, as well as the importance of answering all questions. Finally, regarding the administration of the questionnaires, these were handed out in person, whenever possible, to the health professionals. They consist in self-administered questionnaires, without a time limit, and in order to safeguard the confidentiality and anonymity of the respondents, a properly sealed and identified cardboard box was left in each service, to place the questionnaires in after they were properly filled out and sealed in the envelope that was attached for the effect. The questionnaires were administered in the following order: 1) Sociodemographic questionnaire; and 2) the Job Descriptive Index (JDI) which contains a job in general scale (JIG-Job in General). These stages occurred over two years.

Quantitative methods were used and a correlational, inferential, and descriptive approach was privileged. The observation plan was made up of a cross-sectional study, where both questionnaires identified above were used, to assess the importance of satisfaction in the workplace of various groups of professionals of the SAGH, according to the independent variable under study.

\section{Results}

In order to characterize job satisfaction, descriptive statistics were used for the total of the Job Descriptive Index (JDI/JIG) and respective scales, with the results presented in Table 3.

Considering the cut-off points of $32-22$ (previously explained), it appears 
that the average of the Total Scale of the JDI/JIG is slightly lower than expected in order to be considered satisfaction ( $>32)$. However, it is important to highlight that the value $(M=31.54)$ is very close to the cut-off point. Regarding the other scales, only two reveal dissatisfaction: Wage $(M=17.73)$ and Opportunities for promotion $(M=14.47)$. As for the scales Characterization of Current Job $(M=39.73)$, Supervision $(M=38.59)$, Coworkers $(M=37.80)$, and Job in General $(M=40.90)$, they display values over 32, suggesting satisfaction.

Regarding the analyses performed in Table 4 and Table 5 , statistically significant differences were found $\left({ }^{\star} p \leq 0.05 ;{ }^{* *} p \leq 0.01\right)$ in terms of the level of job satisfaction according to age, marital status, qualifications, employment status, professional category, working hours, performance of managerial duties, relationship with superiors and with coworkers, the value the individual perceives being attributed to him/her by superiors, of the motivation/satisfaction that the individual feels when performing his/her job, of the level of satisfaction that the individual feels in relation to his/her wage, and alcohol consumption. It was found that younger professionals show higher levels of satisfaction in terms of the total scale and in terms of their relationship with coworkers. In regards to qualifications, it is the participants with degrees who reveal greater satisfaction with their current job and with their relationship with coworkers. Similar results were achieved by McCormick (2000). Regarding marital status, single participants displayed higher satisfaction in relation to their coworkers, whereas participants who were in de facto unions showed higher satisfaction towards their job in general. As for employment status, participants with permanent contracts showed higher levels of satisfaction, comparatively to those with a fixed term contract, in the job in general dimension. As for professional category, it is the Nurses and Doctors who reveal greater satisfaction. These results are in accordance with the study by McIntyre, McIntyre, \& Silvério (2000). With regard to working hours, in general terms, it was found that professionals who practice rotating day and night shifts suggest a higher level of satisfaction. Similar results were found by Dwyer, Jamieson, Moxham, Austen, \& Smith (2007).

The results of this study also showed that participants who expressed a more positive relationship towards both their coworkers and superiors, and, if they felt valued by their superiors, they showed a higher level of job satisfaction. Participants who revealed a greater feeling of motivation/satisfaction also suggested higher job satisfaction. In particular, the greater the satisfaction with their wage was, the greater their level of job satisfaction. It was also observed that participants who do not consume or consume very little alcohol showed greater job satisfaction. The studies by McIntyre et al. (2000), Unterweger, Imhof, Mohr, Römpler, \& Kubit-Huch (2007), Haddon, Shuman, \& Khein (1964), and Castro (2002) refer similar results.

It was also found that participants who performed managerial duties (Table 5) expressed greater satisfaction towards the Characterization of Current Job dimension. Similar results have also been achieved by Green, Ross, \& Weltz, 1999, and Miller \& Wheeler, 1992. 
F. Almeida et al.

Table 4. Degree of Satisfaction at work (JDI/JIG) as a function of socio-demographic variables

\begin{tabular}{|c|c|c|c|c|c|c|c|}
\hline Scale & Age & $M$ & $N$ & $S D$ & $G l$ & $F$ & $p$ \\
\hline Coworkers & 20 to 29 years & 41.49 & 63 & 10.76 & $3 / 147$ & 3.691 & $0.013^{*}$ \\
\hline \multirow[t]{2}{*}{ Total Scale } & 20 to 29 years & 33.42 & 63 & 7.38 & $3 / 147$ & 2.754 & $0.045^{\star}$ \\
\hline & Marital Status & $M$ & $N$ & $S D$ & Gl & $F$ & $P$ \\
\hline Coworkers & Single & 40.96 & 58 & 10.86 & $4 / 148$ & 2.685 & $0.034^{\star}$ \\
\hline \multirow[t]{2}{*}{ General work } & Committed & 45.20 & 5 & 8.81 & $4 / 148$ & 2.737 & $0.031^{*}$ \\
\hline & $\begin{array}{c}\text { Educational } \\
\text { Qualifications }\end{array}$ & $M$ & $N$ & $S D$ & Gl & $F$ & $p$ \\
\hline $\begin{array}{c}\text { Characterization } \\
\text { current job }\end{array}$ & Graduation & 42.85 & 81 & 10.42 & $4 / 148$ & 3.856 & $0.005^{\star}$ \\
\hline \multirow[t]{2}{*}{ Coworkers } & Graduation & 40.29 & 81 & 11.41 & $4 / 148$ & 3.114 & $0.016^{*}$ \\
\hline & Professional Status & $M$ & $N$ & $S D$ & Gl & $F$ & $p$ \\
\hline \multirow[t]{2}{*}{ General work } & $\begin{array}{c}\text { Individual } \\
\text { employment contract } \\
\text { of indefiniteduration }\end{array}$ & 43.43 & 39 & 8.22 & $6 / 143$ & 2.361 & $0.033^{\star}$ \\
\hline & $\begin{array}{c}\text { Profissional } \\
\text { category }\end{array}$ & $M$ & $N$ & $S D$ & $G l$ & $F$ & $p$ \\
\hline $\begin{array}{c}\text { Characterization } \\
\text { current job }\end{array}$ & Doctor & 47.84 & 13 & 6.85 & $5 / 148$ & 5.355 & $0.000^{*}$ \\
\hline $\begin{array}{c}\text { Characterization } \\
\text { current job }\end{array}$ & Nurse & 42.56 & 65 & 8.27 & $5 / 148$ & 5.355 & $0.000^{*}$ \\
\hline Coworkers & Doctor & 39.61 & 13 & 11.41 & $5 / 148$ & 6.169 & $0.000^{*}$ \\
\hline Coworkers & Nurse & 41.64 & 65 & 10.77 & $5 / 148$ & 6.169 & $0.000^{*}$ \\
\hline General work & Doctor & 42.76 & 13 & 6.74 & $5 / 148$ & 3.429 & $0.010^{*}$ \\
\hline \multirow[t]{2}{*}{ General work } & Nurse & 42.61 & 65 & 8,11 & $5 / 148$ & 3,429 & $0.010^{*}$ \\
\hline & Office hours & $M$ & $N$ & $S D$ & Gl & $F$ & $p$ \\
\hline \multirow[t]{2}{*}{ Supervision } & $\begin{array}{c}\text { Day and } \\
\text { nigh trotating shifts }\end{array}$ & 41.18 & 99 & 12.84 & $4 / 148$ & 3.328 & $0.012^{*}$ \\
\hline & $\begin{array}{c}\text { Higher } \\
\text { hierarchical relations }\end{array}$ & $M$ & $N$ & $S D$ & Gl & $\mathrm{F}$ & $p$ \\
\hline \multirow[t]{2}{*}{ Total } & Very good & 35.07 & 37 & 6.24 & $4 / 147$ & 13.529 & $0.0001^{* *}$ \\
\hline & Labour motivation & $M$ & $N$ & $S D$ & Gl & $F$ & $p$ \\
\hline \multirow[t]{2}{*}{ Total } & Always & 35.92 & 33 & 5.31 & $5 / 148$ & 13.078 & $0.0001^{* *}$ \\
\hline & Labour satisfaction & $M$ & $N$ & $S D$ & Gl & $F$ & $p$ \\
\hline \multirow[t]{2}{*}{ Total } & Very satisfied & 36.67 & 41 & 5.19 & $3 / 148$ & 24.344 & $0.0001^{\star *}$ \\
\hline & Salarysatisfaction & $M$ & $N$ & $S D$ & $G 1$ & $F$ & $p$ \\
\hline \multirow[t]{2}{*}{ Total } & Satisfied & 35.72 & 32 & 7.74 & $3 / 146$ & 8.815 & $0.0001^{\star *}$ \\
\hline & Alcohol use & $M$ & $N$ & $S D$ & $G l$ & $F$ & $p$ \\
\hline Total & $\begin{array}{c}\text { I do not } \\
\text { commitexcesses }\end{array}$ & 35.62 & 9 & 4.25 & $4 / 415$ & 2.858 & $0.026^{* *}$ \\
\hline
\end{tabular}


Table 5. Degree of Satisfaction at work (JDI/JIG) due to the exercise of management functions

\begin{tabular}{|c|c|c|c|c|c|c|c|}
\hline Scale & Leading roles & $M$ & $N$ & $M D$ & $G l$ & $t$ & $p$ \\
\hline \multirow{2}{*}{$\begin{array}{c}\text { The current } \\
\text { job characterization }\end{array}$} & Yes & 49.10 & 10 & 13.77 & \multirow{2}{*}{145} & \multirow{2}{*}{2.23} & \multirow{2}{*}{$0.05^{\star}$} \\
\hline & No & 39.16 & 137 & 11.13 & & & \\
\hline
\end{tabular}

${ }^{*} p \leq 0.05 ;{ }^{* *} p \leq 0.01$.

The chi-square test was used, in order to characterize absenteeism. The results suggested that, for the year 2005, it was the younger participants, single and divorced, who belonged to the nurse and general services professional category that revealed less absenteeism. It was also found that participants with less absence from work were those who showed greater levels of job motivation/satisfaction. As for the reasons for the absence, the most satisfied participants were those who reported lower rates of physical and mental illness. Similar results were found in the studies by Burke (1969, 1970, in Locke, 1976), Ripon (1987), Robbins (2001), and Herzberg, Mausner, \& Snyderman (1959). These results were not corroborated for the year 2006, where older participants who were satisfied with the wage dimension revealed less absence from work. It was also found that participants, who were single and in a de facto union, practiced rotating day and night shifts, did not perform duties in other institutions and did not smoke, revealed less absenteeism. As for the reasons behind the absence, it was the married participants, who practiced fixed day shifts, did not perform managerial duties and possessed a better relationship with coworkers that presented higher manifestations of physical disease. Statistically significant associations were also found concerning marital status and working conditions, with participants who were in a de facto union attributing greater absenteeism to poor working conditions.

\section{Discussion}

As for employment status, the data that was obtained suggested that participants with a permanent contract exhibit a greater level of satisfaction comparatively to those with a fixed term contract, in the job in general dimension. As an attempt to explain these results, it can be presumed that professionals with a permanent contract feel more secure and, consequently, experience greater stability and job satisfaction. As for working hours, the results showed that professionals who practice rotating day and night shifts are those who suggest greater levels of satisfaction. A way to explain these results may be the fact that professionals have free day hours and more schedule options, which may lead them to feel greater job satisfaction. In general, there were also high levels of motivation and job satisfaction. In particular, the greater the satisfaction with wage was, the greater the level of job satisfaction. However, in general, the results indicate greater dissatisfaction in relation to the wage and opportunities for promotion dimensions. These facts may be related to the perceptions the professional exhibit in relation 
to their wage and opportunities for promotion. They perceive their wage as insufficient and associated to scarce and precarious opportunities for promotion. It was also possible to conclude that, for the year 2005, the younger participants, single and divorced, who belonged to the nurse and general services professional category, exhibited less absenteeism. It was also observed that participants with fewer absent days were those who presented higher levels of job satisfaction and motivation. As for the reasons behind the absent days (physical illness, mental illness, mental illness/psychological ill-being originated by conflicts), it was found that the most satisfied participants were those who revealed less manifestations of physical and mental illness. As an attempt to support the observed results, we were led to presume, on the one hand, the fact that the professionals feel satisfied by their job is a motive to not deliberately miss work; on the other hand, the fact that the most satisfied workers manifest less physical and mental illness seems to be associated to some characteristics of the participants, namely, most of them being youth between 20 and 29 years of age (42.6\%), non-smokers (73.5\%), who do not consume alcohol (42.3\%) nor drugs (98.0\%) and who practice physical exercise, although irregularly (43.6\%). The age factor and such behaviors seem to be the cause and/or contribute to a good standard of physical and mental health, which will enable them to enjoy better health, and, consequently, less absence from work. The state of satisfaction and motivation they feel towards their job seems to allow them to also get sick less frequently.

Concerning the year 2006, it was found that the participants who were more satisfied with their wage exhibited less absent days. This result may be explained by the fact that the Santo António General Hospital offers an incentive for productivity/monthly attendance, that is, all workers from all professional categories, with individual work contracts, are entitled to an incentive corresponding to about $20 \%$ of their wage, if they do not have absences of more than one day a month. As for the age factor, it was found that older participants had fewer absent days. One way of trying to explain these results is to presume that older participants mostly have a higher level of responsibility and, therefore, are less absent from work. In the present study, it was found that participants who were single and are in de facto union, practiced rotating day and night shift, did not perform duties in other institutions and did not smoke, revealed less absenteeism. As an effort to explain these results, we were led to presume that the fact that a vast majority of professionals are single, and due to this condition, do not have additional responsibilities, is a reason for being less absent from work. The fact that they practice rotating day and night shifts leads us to suspect that this allows them to enjoy free day hours, as well as greater schedule options, and, for that reason, they feel more satisfied, which leads to less absenteeism. Literature suggests that flexible working hours may be beneficial, as it enables professionals to have time for their personal affairs (Cobau \& Pearson, 1993). The fact that they do not perform duties in other institutions and they do not smoke, also contributes to less absent days, since they may not suffer increased fatigue caused by their profession, namely derived from excessive workload. The fact 
that they do not smoke also suggests a better level of health for the workers, hence significantly lower absenteeism. In regards to the reasons for absenteeism in 2006, contrary to expectations, it was the married participants, who practice fixed day shifts, did not perform managerial duties and had a better relationship with coworkers that displayed higher manifestations of physical illness. A possible explanation for these results relates to the fact that the participants are married and thus have increased family duties (including children who fall ill), as well as the fact that the majority of them have a permanent individual contract, which grants them more security and allows them to miss work without the fear of losing their job. The fact that they do not perform managerial duties and have a good relationship with coworkers also enables greater facilitation of absence from work, given that the responsibilities are less, compared to those who exercise managerial duties, and are more easily ensured by coworkers. These results may also be related to issues of personal vulnerability, which leads us to believe that, in order to maintain a good relationship with coworkers, participants do not externalize their emotions, thus avoiding conflict. Such behavior may lead to somatization, that is, the appearance of symptoms/physical illness.

Caution should be exercised with the results obtained in this study, since these relate to a specific institution and are therefore not subject to generalizations for other institutions or professionals. The results obtained point to the need for new studies, since the literature has not been conclusive about the variables that help to promote better and more responsible interpersonal relationships in the workplace and wages that are perceived as fair, that is, factors that are directly related to job (dis) satisfaction. In this study, with professionals who work in the hospital area, this reality is worrying, as there will be a compromise in the quality of care that is provided to the patient and to the entire social network involved.

\section{Conclusion}

It is also possible to conclude that the factors associated to greater absenteeism are: stable bond if the individuals do not have managerial duties; less satisfaction with wage (the perception may not translate what is fair); lower quality of interpersonal relationships with coworkers and superiors (a factor as valued as wage, or even more so). On the other hand, the existence of an incentive for productivity/monthly attendance is associated to less absenteeism.

This means that the results of this study reveal, both in practice and according to an organizational approach, the need for programs that promote better and more responsible interpersonal relationships in the workplace, wages that are perceived as fair and adequate benefit policies.

\section{Conflicts of Interest}

The authors declare no conflicts of interest regarding the publication of this paper. 


\section{References}

Albaladejo, R., Villanueva, R., Ortega, P., Astasio, P., Calle, M., \& Domínguez, V. (2004). Burnout Syndrome in the Nursing Staff of a Hospital in Madrid. Revista Española de Salud Pública, 78, 505-516. https://doi.org/10.1590/S1135-57272004000400008

Benevides-Pereira, A. (2002). Burnout: O processo de adoecer pelo trabalho. In Benevides-Pereira (Ed.), Burnout: When Work Threatens Worker's Welfare (pp. 21-91). São Paulo: Casa do Psicólogo.

Bulhões, I. (1986). Nursing Work. Rio de Janeiro: IDEAS.

Castro, K. (2002). Alcohol and Work: A Worker's Experience of a Public University of Rio de Janeiro. Master's Dissertation in Public Health, Rio de Janeiro: School of Public Health, Oswaldo Cruz Foundation, Health, Work and Environment Sub-Area.

Cobau, G., \& Pearson, S. (1993). Absenteeism. Lisboa: Gradiva-Publicações, Lda.

Dwyer, T., Jamieson, L., Moxham, L., Austen, D., \& Smith, K. (2007). Evaluation of the 12-Hour Shift Trial in a Regional Intensive Care Unit. Journal Nursing Management, 15, 711-720. https://doi.org/10.1111/j.1365-2934.2006.00737.x

Green, T., Ross, J., \& Weltz, J. (1999). Job Satisfaction and Organizational Commitment. In C. L. Cooper, \& I. T. Robertson (Eds.), International Review of Industrial Psychological (pp. 157-188). New York: John Willey \& Sons.

Haddon, W., Suchman, E., \& Klein, D. (1964). Accident Research. New York: Harper and Row.

Happel, B., Martin, T., \& Pinikahana, J. (2000). Burnout and Job Satisfaction: A Comparative Study of Psychiatric Nurses from Forensic and a Mainstream Mental Health Service. International Journal of Mental Health Nursing, 12, 39-47. https://doi.org/10.1046/j.1440-0979.2003.00267.x

Herzberg, F., Mausner, B., \& Snyderman, B. (1959). The Motivation to Work. New York: John Willey \& Sons.

Herzberg, F., Mausner, B., Peterson, R., \& Capwell, D. (1957). Job Attitudes: Review or Research and Opinion. Pittsburgh, PA: Psychological Service of Pittsburgh.

Ilghen, D. R., \& Hollenbeck, J. (1977). The Role of Job Satisfaction in Absence Behaviour. Organizational Behaviour and Human Performance, 19, 148-161. https://doi.org/10.1016/0030-5073(77)90059-9

Ironson, G., Smith, P., Brannick, M., Gibson, W., \& Paul, K. (1989). Constitution of a Job in General Scale: A Comparison of Global, Composite, and Specific Measures. Journal of Applied Psychology, 74, 193-200. https://doi.org/10.1037/0021-9010.74.2.193

Locke, E. (1969). What Is Job Satisfaction? Organizational Behavior and Human Performance, 4, 309-336. https://doi.org/10.1016/0030-5073(69)90013-0

Locke, E. (1976). The Nature and Causes of Job Satisfaction. In M. D. Dunette (Ed.), Handbook of Industrial and Organizational Psychology (pp. 1297-1343). Chicago, IL: Rand Mcnally.

McCormick, C. (2000). A Study of Job Attitudes (Job Satisfaction, Organizational Commitment and Career Commitment) and Career Adaptability of the Members of the Library and Information Science Profession. http://www.vla.org/programs/MLAVLASummary.html

McIntyre, T., McIntyre, S., \& Silvério, J. (2000). In-Depth Study of Professional Satisfaction, Stress and Coping Resources of Health Professionals in the North Region. Estudo realizado no âmbito do protocolo estabelecido entre a Administração Regional de Saúde do Norte e a Universidade do Minho. 
Miller, J., \& Wheeler, K. (1992). Unraveling the Mysteries of Gender Differences in Intentions to Leave the Organization. Journal of Organizational Behavior, 13, 465-478. https://doi.org/10.1002/job.4030130504

Monteiro, L., \& Caetano, A. (1994). Social Psychology of Organizations, Studies in Portuguese Companies. Oeiras: Celta.

Nogueira, D. (1984). Incorporation of Occupational Health into the Primary Health Network. Revista Saúde Pública, 18, 495-509. https://doi.org/10.1590/S0034-89101984000600009

Pines, A., \& Aronson, E. (1989). Career Burnout: Causes and Cures (pp. 80-96). New York: The Free Press.

Porter, L., \& Steers, R. (1973). Organizational, Work and Personal Factors in Employee Turnover and Absenteeism. Psychological Bulletin, 80, 151-176. https://doi.org/10.1037/h0034829

Ripon, A. (1987). Satisfaction et implication dans le travail. In Lévy-Leboyer, \& Spérandio (Eds.), Traité de Psychologie du Travail (pp. 421-434). Paris: PUF.

Robbins, S. (2001). Organizational Behaviour. Upper Saddle River, NJ: Prentice Hall.

Smith, P., Kendall, M., \& Hulin, C. (1969). The Measure of Job Satisfaction and Retirement. Chicago, IL: Margem McNally.

Tylczak, L. (1993). Fighting Absenteeism-Positive Solutions to an Old Problema. Lisboa: Monitor.

Unterweger, M., Imhof, S., Mohr, H., Römpler, M., \& Kubik-Huch, R. (2007). Which Factors Influence Job Satisfaction and Motivation in an Institute of Radiology? Schweizerische Rundschau fur Medizin Praxis, 96, 1299-1306.

https://doi.org/10.1024/1661-8157.96.35.1299

Vroom, V. (1964). Work and Motivation. New York: Wiley.

Zedeck, S. (1987). Satisfaction in Marriage Members and Their Spouses. Ohio, OH: Verde Rolar. 